\title{
Laparoscopic liver resection in the cirrhotic patient
}

\author{
Ben Robichaux ${ }^{1}$, Jesse Sulzer ${ }^{1}$, Joseph F. Buell ${ }^{1,2}$ \\ ${ }^{I}$ Department of Surgery, Louisiana State University School of Medicine, Baton Rouge, LA 70803, USA. \\ ${ }^{2}$ Tulane Transplant Institute, Departments of Surgery, Tulane University School of Medicine, New Orleans, LA 70112, USA.
}

Correspondence to: Prof. Joseph F. Buell, Director of Tulane Transplant Institute, Departments of Surgery, Tulane University School of Medicine, 1415 Tulane Avenue, New Orleans, LA 70112, USA. E-mail: jbuell1@tulane.edu

How to cite this article: Robichaux B, Sulzer J, Buell JF. Laparoscopic liver resection in the cirrhotic patient. Hepatoma Res 2016;2:248-52.

Article history:
Received: $17-06-2016$
Accepted: $05-07-2016$
Published: $19-09-2016$
Key words:
Laparoscopic liver resection,
cirrhosis,
complications,
outcomes

\begin{abstract}
\end{abstract}
\section{INTRODUCTION}

Liver resection has dramatically evolved over the last four decades. Initial series incurred high morbidity and mortality rates. ${ }^{[1,2]}$ However, with the introduction of modern anesthesia and improved knowledge of the surgical anatomical segments the mortality decreased to acceptable levels lending to the proliferation of resection programs. ${ }^{[3-5]}$ In the last decade we have witnessed a second proliferation of hepatic resections attributed to the introduction of the laparoscopic technique. ${ }^{[6,7]}$ However, the greatest challenge in the resection of hepatic tumors remains their management in the setting of cirrhotic liver. ${ }^{[8,9]}$

Despite the introduction of effective antivirals for the treatment of hepatitis $\mathrm{C}$, the incidence of cirrhosis is expected to continually rise worldwide most frequently attributed to the ever increasing prevalence of obesity, fatty liver disease and non alcoholic steato hepatitis. ${ }^{[10]} \mathrm{A}$ 
Table 1: Patient demographics

\begin{tabular}{lccc}
\hline & Open & Laparoscopic & P-value \\
\hline Number & 39 & 75 & 0.152 \\
Age (years) & $58.1 \pm 12.8$ & $61.3 \pm 9.86$ & $0.007^{*}$ \\
Male gender (\%) & $89.7 \pm 30.7$ & $66.7 \pm 47.5$ & 0.486 \\
Government insurance (\%) & $25.6 \pm 44.2$ & $32.0 \pm 47.0$ & 0.713 \\
BMI & $28.2 \pm 6.0$ & $27.8 \pm 4.9$ & 0.494 \\
HTN (\%) & $74.4 \pm 44.2$ & $80.0 \pm 40.3$ & 0.664 \\
DM (\%) & $33.3 \pm 47.8$ & $30.7 \pm 40.2$ & 0.638 \\
INR & $1.1 \pm 0.2$ & $1.1 \pm 0.1$ & 0.071 \\
Bilirubin & $0.83 \pm 0.42$ & $0.691 \pm 0.36$ & $0.013^{*}$ \\
Creatinine & $1.05 \pm 0.58$ & $0.86 \pm 0.24$ & 0.357 \\
PLT & $187.5 \pm 87.2$ & $173.4 \pm 73.7$ & 0.054 \\
Varicies (\%) & $33.3 \pm 47.7$ & $17.3 \pm 38.1$ & 0.130 \\
Ascites (\%) & $2.6 \pm 47.7$ & $10.7 \pm 31.1$ & $0.020^{*}$ \\
ASA score & $3.3 \pm 0.5$ & $3.1 \pm 0.3$ & $<0.001^{*}$ \\
Tumor size (cm) & $6.56 \pm 4.26$ & $3.20 \pm 2.01$ & \\
\hline
\end{tabular}

*Statistically significant. BMI: body mass index; HTN: hypertension; DM: diabetes mellitus; INR: international normalized ratio; PLT: platelet; ASA American Society of Anesthesiologists

significant proportion of these cirrhotic patients will present for the management of hepatocellular cancer. ${ }^{[11]}$ However, with the incidence of cirrhosis ever rising in the general population, other pathologic lesions will be presented for diagnosis and surgical management including symptomatic benign tumors, colorectal metastases and in the era of increasing resolution imaging indeterminate lesions.

This study examines our experience with laparoscopic liver resection in cirrhotic patients for multiple pathologies. The aim of the current study was to elucidate the potential benefits of laparoscopic liver resection over open hepatic resection in the management of surgically resectable liver lesions in cirrhotic patients.

\section{METHODS}

This is a retrospective study analyzing the effect of a laparoscopic approach on the resection of liver tumors in cirrhotic patients. The current study was submitted and approved by an institutional review board at our institution. One hundred and fourteen cirrhotic liver resections were identified in a surgical database performed by a single surgeon. The cohort of cirrhotic resections was evaluated for patient demographics, operative outcomes, morbidity, mortality, and longterm patient survival. The impact of laparoscopic liver resection was then compared to the open liver resection group. Further examination was performed using a subset analysis to evaluate the extent of resection. Major resections were defined as in prior studies as removal of three or greater segments.

The surgical evaluation and resection techniques used during this study were identical throughout the series. All resection candidates were evaluated with an established criterion including: preoperative imaging with triphasic computed tomography scan or contrasted magnetic resonance imaging, estimation of functional liver remnant, confirmation of platelet count, and selective measurement of transjugular wedge pressures. In the setting of high risk patients such as platelet counts less than $100 \mathrm{~K}$ or presence of significant varicies, transhepatic wedge pressures and extent of resection dictated the decision to proceed with resection and in marginal cases portal vein embolization was employed. Both open and laparoscopic resections were performed using a parenchymal sparing intent with the aid of low central venous pressures, and parenchymal division with an ultrasonic dissector and stapler hepatectomy.

Patient demographics, tumor characteristics, operative and postoperative outcome data were collected and analyzed. Data was reported with means and standard deviations. Statistical comparisons were calculated and analyzed using SAS software. Significant differences were identified at a $P$-value of $<0.05$. Multivariate regression analysis was then applied to evaluate the effects of laparoscopic liver resection on patient morbidity, mortality and readmission.

\section{RESULTS}

The study cohort of cirrhotic resection patients was composed of 114 cirrhotic patients. The laparoscopic liver resection group was comprised of 75 patients $(65.8 \%)$ and the open liver resection group 39 patients. Age, gender, race, and demographics were all similar between the 2 groups [Table 1]. The tumor size was significantly larger in the open resection group while the preoperative diagnosis and etiology of cirrhosis were similar.

The operative outcomes were noted to have significant 
Table 2: Patient outcomes by technique of resection

\begin{tabular}{lccc}
\hline & Open & Laparoscopic & $P$-value \\
\hline Number & 39 & 75 & $<0.001^{*}$ \\
Major resections (\%) & $66.7 \pm 47.7$ & $16.3 \pm 36.9$ & $<0.001^{*}$ \\
OR time (h) & $4.8 \pm 2.0$ & $2.4 \pm 1.1$ & $<0.001^{*}$ \\
EBL (mL) & $609.0 \pm 603.8$ & $250.7 \pm 344.6$ & $0.012^{*}$ \\
Transfusion (\%) & $38.5 \pm 49.3$ & $17.3 \pm 38.1$ & 0.269 \\
Margin (cm) & $1.05 \pm 0.8$ & $0.90 \pm 0.6$ & $<0.001^{*}$ \\
ICU admission (\%) & $89.7 \pm 30.7$ & $32.0 \pm 49.8$ & $0.028^{*}$ \\
Complications (\%) & $48.7 \pm 50.5$ & $28.0 \pm 45.2$ & $0.013^{*}$ \\
LOS (days) & $10.1 \pm 18.3$ & $4.4 \pm 3.8$ & 0.926 \\
90-day readmissions (\%) & $15.4 \pm 36.6$ & $14.6 \pm 35.7$ & 0.502 \\
90-day mortality (\%) & $5.1 \pm 22.4$ & $2.7 \pm 16.2$ & \\
\hline
\end{tabular}

*Statistically significant. OR: operating room; EBL: estimated blood loss; ICU: intensive care unit; LOS: length of stay

Table 3: Patient outcomes analyzed by extent and technique of resection

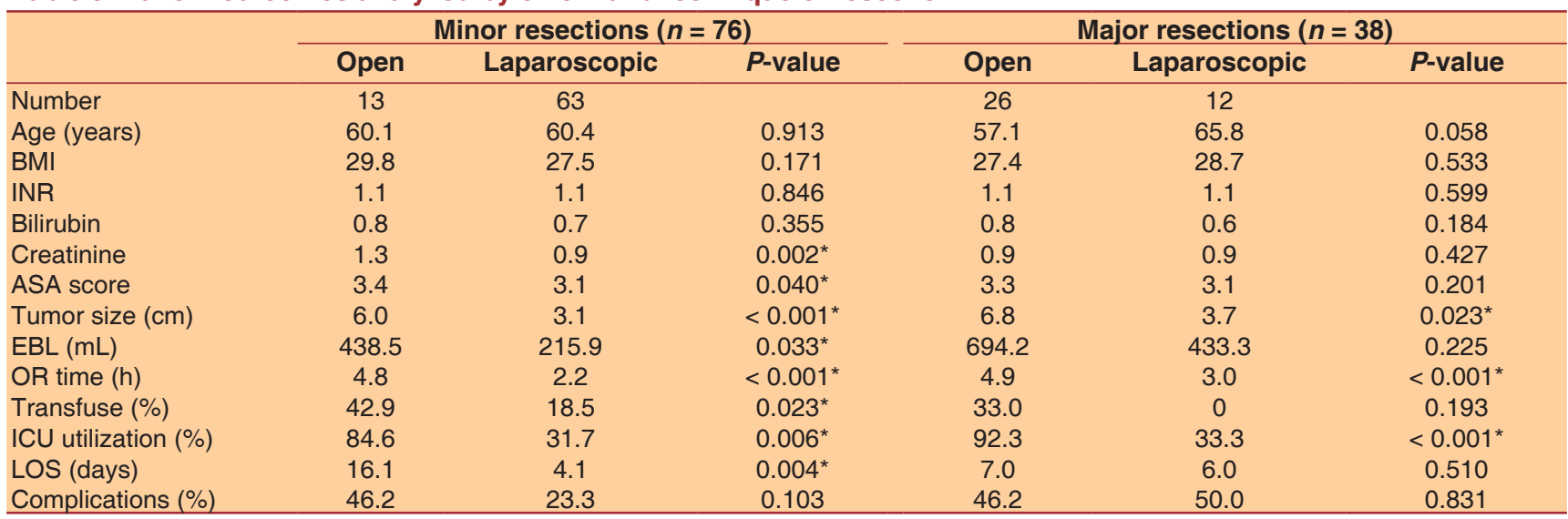

*Statistically significant. BMI: body mass index; INR: international normalized ratio; ASA: American Society of Anesthesiologists; EBL: estimated blood loss; OR: operating room; ICU: intensive care unit; LOS: length of stay

differences in resection extent, bleeding, transfusions, and operative times [Table 2]. Length of stay, and complications were significantly different while the readmission and mortality rates were not dramatically different [Table 2]. Seventy-six $(66.7 \%)$ resections were minor in extent with $63(82.9 \%)$ of them performed through the laparoscope. Thirty-eight resections in this series were major as defined by removal of 3 or more segments with $12(31.6 \%)$ removed through the laparoscope. Minor and major resections witnessed a reduction in operative times, ICU utilization and length of stay. Blood loss and complications were significantly less in the laparoscopy group only in minor resection. The previously described advantages were not identified in the major resection subgroup [Table 3]. Multivariate analysis for bleeding identified open resection $(P=0.014)$ and major resection $(P$ $=0.026)$ as significant risk factors for blood loss. In subset analysis only international normalized ratio $(P$ $=0.018)$ was significant in the major resection group. Multivariate analysis identified tumor size $(P=0.023)$ as a risk for complications. In subset analysis this persisted while in major resections this effect was lost. Multivariate analysis for death identified creatinine $(P$ $=0.016)$, bilirubin $(P=0.019)$, and obesity defined by body mass index $(\mathrm{BMI})>35(P=0.043)$. Creatinine $(P$ $<0.001)$ and BMI $(P=0.019)$ persisted in significance in minor resection but was lost in major resections.

\section{DISCUSSION}

Liver resection in the cirrhotic patient is significantly more complex than in the non cirrhotic patient. ${ }^{[12-14]}$ Cirrhotic patients are frequently metabolically compromised, coagulopathic and may suffer from a degree of portal hypertension. However, the most dreaded complication of hepatic resection in the cirrhotic patient is post-operative liver failure resulting from an inadequate functional liver remnant. Decades of efforts in preoperative assessment including metabolic challenge of the liver with indomethacin green and calculated functional liver remnant have been critical in reducing operative mortality. ${ }^{[15,16]}$

Since the initial Louisville Consensus Conference, there have been over 500 cases of laparoscopic resection for hepatocellular carcinoma reported in the literature. ${ }^{[17-21]}$ Most patients in this group are cirrhotic, but a considerable percentage were noncirrhotic or pre-cirrhotic arising in the setting of chronic 
hepatitis. Multiple studies have confirmed the benefits of laparoscopic liver resection in decreasing operative times, bleeding, complications and length of stay in non cirrhotic patients. ${ }^{[22-25]}$ Most cirrhotic resection data has been included into larger hepatocellular cancer reports making assessment of this data questionable at best. However, a recent meta analysis of laparoscopic resection of hepatocellular cancer in cirrhotic patients confirmed this approach was associated with a reduced risk of transfusion, decreased length of stay and wider surgical margins but failed to identify a difference in operative times, and morbidity. ${ }^{[26]}$ This is in contrast to a smaller French case-controlled study that identified laparoscopic resection resulted in shorter operative times, hospital stays and lower morbidity rates. ${ }^{[27]}$

Our current data presented in this study confirms laparoscopic resection in cirrhotics provide shorter operative times, blood loss, transfusion, intensive care utilization, length of stay, and post operative complications. However, when operative outcomes were analyzed in regard to the extent of resection the laparoscopic group persisted in shorter operative times with less intensive care utilization while reduction of blood loss and shorter lengths of stay were not realized in the major resection group.

Multiple studies have attributed the advantages of laparoscopic liver resections to a less aggressive approach, minimizing peritoneal dissection, and bleeding leading to lower incidence of ascites and posthepatectomy liver failure. ${ }^{[19-22]}$ Two authors have even suggested laparoscopic liver resection may extend the indication of liver resection into selected Child B patients. ${ }^{[20,28]}$ Our experience with would support this supposition in well selected Child B patients. An additional advantage of laparoscopic liver resection of was reduction in postoperative adhesions facilitating subsequent liver transplantation with decreased morbidity. This observation was advanced in an article on salvage transplantation after laparoscopic liver resection for hepatocellular cancer. ${ }^{[29]}$ Alternatively, the results reported from the meta analysis indicate all groups have not witnessed such a clear and dramatic advantage with laparoscopic liver resection. ${ }^{[26]}$

Our data would support these general suppositions but identified significant differences in outcome related complications after major laparoscopic resections. This may arise from the significantly increased need for dissection, bleeding and transfusion. Alternatively, this may reflect a steeper and longer learning curve required in the performance of laparoscopic cirrhotic liver resections and most importantly major laparoscopic liver resections in cirrhotics. As observed in early open resection of cirrhotic tumors, these challenges have resulted in greater difficulty in achieving wide resection margins and performing formal anatomical resections, as well as increasing the difficulties in mobilization and in particular parenchymal transection, with risk of massive bleeding. These concerns and potential issues have been the major obstacles to the widespread adoption of laparoscopic liver resection in the management of liver tumors in cirrhotics.

In conclusion, laparoscopic liver resection in cirrhotic patients appears safe and efficacious in experienced centers resulting in overall significantly shorter operative times, lower blood loss, and shorter hospital stays and few complications. In subset analysis several advantages of the laparoscopic approach are lost including lower blood loss and few complications. Our current experience in laparoscopic major resections in cirrhotics has leaded us to reconsider the learning curve and temper our enthusiasm for major resection in cirrhotics. Perhaps with increasing experience these benefits will be realized but currently our group advocates a tempered and highly selective approach to the laparoscopic approach to major cirrhotic resections.

\section{Financial support and sponsorship None.}

\section{Conflicts of interest}

There are no conflicts of interest.

\section{Patient consent}

Not involved.

\section{Ethics approval}

Approved by an institutional review board at authors' institution.

\section{REFERENCES}

1. Lin TY. A simplified technique for hepatic resection: the crush method. Ann Surg 1974;180:285-90.

2. Shiu MH, Fortner JG. Current management of hepatic tumors. Surg Gynecol Obstet 1975;140:781-8.

3. Cucchetti A, Cescon M, Golfieri R, Piscaglia F, Renzulli M, Neri F, Cappelli A, Mazzotti F, Mosconi C, Colecchia A, Ercolani G, Pinna AD. Hepatic venous pressure gradient in the preoperative assessment of patients with resectable hepatocellular carcinoma. J Hepatol 2016;64:79-86.

4. Harimoto N, Shirabe K, Ikegami T, Yoshizumi T, Maeda T, Kajiyama K, Yamanaka T, Maehara Y. Postoperative complications are predictive of poor prognosis in hepatocellular carcinoma. J Surg Res 2015;199:470-7.

5. Dagher I, Gayet B, Tzanis D, Tranchart H, Fuks D, Soubrane O, Han HS, Kim KH, Cherqui D, O’Rourke N, Troisi RI, Aldrighetti L, Bjorn E, Abu Hilal M, Belli G, Kaneko H, Jarnagin WR, Lin C, Pekolj J, Buell JF, Wakabayashi G. International experience for laparoscopic major liver resection. J Hepatobiliary Pancreat Sci 2014;21:732-6.

6. Buell JF, Cherqui D, Geller DA, O'Rourke N, Iannitti D, Dagher I, 
Koffron AJ, Thomas M, Gayet B, Han HS, Wakabayashi G, Belli G, Kaneko H, Ker CG, Scatton O, Laurent A, Abdalla EK, Chaudhury P, Dutson E, Gamblin C, D’Angelica M, Nagorney D, Testa G, Labow D, Manas D, Poon RT, Nelson H, Martin R, Clary B, Pinson WC, Martinie J, Vauthey JN, Goldstein R, Roayaie S, Barlet D, Espat J, Abecassis M, Rees M, Fong Y, McMasters KM, Broelsch C, Busuttil R, Belghiti J, Strasberg S, Chari RS; World Consensus Conference on Laparoscopic Surgery. The international position on laparoscopic liver surgery: the Louisville Statement, 2008. Ann Surg 2009;250:825-30.

7. Wakabayashi G, Cherqui D, Geller DA, Buell JF, Kaneko H, Han HS, Asbun H, O'Rourke N, Tanabe M, Koffron AJ, Tsung A, Soubrane O, Machado MA, Gayet B, Troisi RI, Pessaux P, Van Dam RM, Scatton O, Abu Hilal M, Belli G, Kwon CH, Edwin B, Choi GH, Aldrighetti LA, Cai X, Cleary S, Chen KH, Schön MR, Sugioka A, Tang CN, Herman P, Pekolj J, Chen XP, Dagher I, Jarnagin W, Yamamoto M, Strong R, Jagannath P, Lo CM, Clavien PA, Kokudo N, Barkun J, Strasberg SM. Recommendations for laparoscopic liver resection: a report from the second international consensus conference held in Morioka. Ann Surg 2015;261:619-29.

8. Hackl C, Schlitt HJ, Renner P, Lang SA. Liver surgery in cirrhosis and portal hypertension. World J Gastroenterol 2016;22:2725-35.

9. van Meer S, van Erpecum KJ, Sprengers D, Coenraad MJ, Klümpen HJ, Jansen PL, IJzermans JN, Verheij J, van Nieuwkerk CM, Siersema $\mathrm{PD}$, de Man RA. Hepatocellular carcinoma in cirrhotic versus noncirrhotic livers: results from a large cohort in the Netherlands. Eur J Gastroenterol Hepatol 2016;28:352-9.

10. Charrez B, Qiao L, Hebbard L. Hepatocellular carcinoma and nonalcoholic steatohepatitis: the state of play. World $J$ Gastroenterol 2016;22:2494-502.

11. Zoller H, Tilg H. Nonalcoholic fatty liver disease and hepatocellular carcinoma. Metabolism 2016;65:1151-60.

12. Renner P, Schuhbaum J, Kroemer A, Zeman F, Loss M, Lang SA, Geissler EK, Schlitt HJ, Farkas SA. Morbidity of hepatic resection for intermediate and advanced hepatocellular carcinoma. Langenbecks Arch Surg 2016;401:43-53.

13. Zhang EL, Liang BY, Chen XP, Huang ZY. Severity of liver cirrhosis: a key role in the selection of surgical modality for Child-Pugh A hepatocellular carcinoma. World J Surg Oncol 2015;13:148.

14. Dai Y, Li C, Wen TF, Yan LN. Comparison of liver resection and transplantation for Child-pugh A cirrhotic patient with very early hepatocellular carcinoma and portal hypertension. Pak J Med Sci 2014;30:996-1000

15. Mise Y, Sakamoto Y, Ishizawa T, Kaneko J, Aoki T, Hasegawa K, Sugawara Y, Kokudo N. A worldwide survey of the current daily practice in liver surgery. Liver Cancer 2013;2:55-66.

16. Takasaki T, Kobayashi S, Suzuki S, Muto H, Marada M, Yamana Y, Nagaoka T. Predetermining postoperative hepatic function for hepatectomies. Int Surg 1980;65:309-13.

17. Yamashita Y, Ikeda T, Kurihara T, Yoshida Y, Takeishi K, Itoh S, Harimoto N, Kawanaka H, Shirabe K, Maehara Y. Long-term favorable surgical results of laparoscopic hepatic resection for hepatocellular carcinoma in patients with cirrhosis: a single-center experience over a 10-year period. J Am Coll Surg 2014;219:1117-23.

18. Sposito $\mathrm{C}$, Battiston $\mathrm{C}$, Facciorusso $\mathrm{A}$, Mazzola $\mathrm{M}$, Muscarà $\mathrm{C}$, Scotti M, Romito R, Mariani L, Mazzaferro V. Propensity score analysis of outcomes following laparoscopic or open liver resection for hepatocellular carcinoma. Br J Surg 2016;103:871-80.

19. Chen J, Bai T, Zhang Y, Xie ZB, Wang XB, Wu FX, Li LQ. The safety and efficacy of laparoscopic and open hepatectomy in hepatocellular carcinoma patients with liver cirrhosis: a systematic review. Int J Clin Exp Med 2015;820679-89.

20. Belli A, Cioffi L, Russo G, Belli G. Liver resection for hepatocellular carcinoma in patients with portal hypertension: the role of laparoscopy. Hepatobiliary Surg Nutr 2015;4:417-21.

21. Cheung TT, Lo CM. Laparoscopic liver resection for hepatocellular carcinoma in patients with cirrhosis. Hepatobiliary Surg Nutr 2015;4:406-10.

22. Ettorre GM, Levi Sandri GB, Santoro R, Vennarecci G, Lepiane P, Colasanti M, Felli E, de Werra E, Colace L, D’Offizi G, Montalbano M, Visco U, Maritti M, Antonini M, Santoro E. Laparoscopic liver resection for hepatocellular carcinoma in cirrhotic patients: single center experience of 90 cases. Hepatobiliary Surg Nutr 2015;4:320-4.

23. Shehta A, Han HS, Yoon YS, Cho JY, Choi Y. Laparoscopic liver resection for hepatocellular carcinoma in cirrhotic patients: 10-year single-center experience. Surg Endosc 2016;30:638-48.

24. Santambrogio R, Bruno S, Kluger MD, Costa M, Salceda J, Belli A, Laurent A, Barabino M, Opocher E, Azoulay D, Cherqui D. Laparoscopic ablation therapies or hepatic resection in cirrhotic patients with small hepatocellular carcinoma. Dig Liver Dis 2016;48:189-96.

25. Mamada Y, Yoshida H, Taniai N, Mizuguchi Y, Kakinuma D, Ishikawa Y, Yokomuro S, Arima Y, Akimaru K, Tajiri T. Usefulness of laparoscopic hepatectomy. J Nippon Med Sch 2007;74:158-62.

26. Twaij A, Pucher PH, Sodergren MH, Gall T, Darzi A, Jiao LR. Laparoscopic $v s$. open approach to resection of hepatocellular carcinoma in patients with known cirrhosis: systematic review and meta-analysis. World J Gastroenterol 2014;20:8274-81.

27. Morise Z, Ciria R, Cherqui D, Chen KH, Belli G, Wakabayashi G Can we expand the indications for laparoscopic liver resection? A systematic review and meta-analysis of laparoscopic liver resection for patients with hepatocellular carcinoma and chronic liver disease. $J$ Hepatobiliary Pancreat Sci 2015;22:342-52.

28. Brytska N, Han HS, Shehta A, Yoon YS, Cho JY, Choi Y. Laparoscopic liver resection for hepatitis $\mathrm{B}$ and $\mathrm{C}$ virus-related hepatocellular carcinoma in patients with Child B or C cirrhosis. Hepatobiliary Surg Nutr 2015;4:373-8.

29. Felli E, Cillo U, Pinna AD, De Carlis L, Ercolani G, Santoro R, Gringeri E, Di Sandro S, Di Laudo M, Di Giunta M, Lauterio A, Colasanti M, Lepiane P, Vennarecci G, Ettorre GM. Salvage liver transplantation after laparoscopic resection for hepatocellular carcinoma: a multicenter experience. Updates Surg 2015;67:215-22. 